\title{
CAPITAL MOBILITY, DISTRIBUTIVE CONFLICT AND INTERNATIONAL TAX COORDINATION
}

Dani Rodrik

Tanguy van Ypersele

Working Paper 7150

http://www.nber.org/papers/w7150

\author{
NATIONAL BUREAU OF ECONOMIC RESEARCH \\ 1050 Massachusetts Avenue \\ Cambridge, MA 02138 \\ June 1999
}

We thank Bob Staiger and two anonymous referees for very helpful comments, and Joanna Veltri for editorial assistance. All opinions expressed are those of the authors and not those of the National Bureau of Economic Research.

(C) 1999 by Dani Rodrik and Tanguy van Ypersele. All rights reserved. Short sections of text, not to exceed two paragraphs, may be quoted without explicit permission provided that full credit, including (C) notice, is given to the source. 
Capital Mobility, Distributive Conflict

and International Tax Coordination

Dani Rodrik and Tanguy van Ypersele

NBER Working Paper No. 7150

June 1999

JEL No. F21, F42

\section{ABSTRACT}

Basic economic theory identifies a number of efficiency gains that derive from international capital mobility. But just as free trade in goods, there is no guarantee that capital mobility makes everyone better off. Consequently, capital mobility may be politically unsustainable even though it enhances efficiency. This paper discusses how such a dilemma might arise, and suggests that international tax coordination might serve as a way out under some circumstances.

Dani Rodrik

JFK School of Government

Harvard University

79 Kennedy Street

Cambridge, MA 02138

and NBER

dani_rodrik@harvard.edu
Tanguy van Ypersele

CenTER, Tilburg University

P.O. Box 90153

5000 LE Tilburg

The Netherlands

tanguy@kub.nl 
Basic economic theory identifies a number of efficiency gains that derive from international capital mobility. Free trade in capital allows a superior utilization of resources, the spreading of risk, and ultimately a higher rate of economic growth through the adoption of higher-yield, higher-risk activities (Obstfeld 1994). But just as with free trade in goods, there is no guarantee that capital mobility makes everyone better off. Consequently, capital mobility may be politically unsustainable even though it enhances efficiency. This paper discusses how such a dilemma might arise, and suggests that international tax coordination might serve as a way out under some circumstances.

We focus on a framework with symmetric countries, where the benefits from capital mobility arise from the ability of capital-owners to diversify country-specific risk. As long as shocks to domestic returns to capital are not perfectly correlated across countries, risk-averse capitalists unambiguously benefit from international capital mobility. Risk-averse workers lose, however, since the movement of capital in response to shocks induces fluctuations in real wages and creates a source of risk for labor income. In other words, capital mobility entails a negative externality for workers (Rodrik 1997, chap. 4). Reaping the efficiency gains of capital mobility, therefore, may require finding ways of sharing the benefits with workers.

There is some evidence that national governments, particularly of the left-leaning kind, have recognized the potential adverse effects of capital mobility on workers and have tried to offset it. Focusing on 15 advanced industrial countries over the 1967-90 period, Garrett (1995) finds that governments that have removed controls on capital flows are likely to spend a higher share of GDP, especially if they are run by parties of the left. Higher volumes of trade, reflecting in part greater possibilities of outsourcing, are also correlated with larger public spending in a broad sample of countries (Rodrik 1998).

A subsidy for workers financed by a tax on capital income is the obvious 
remedy for redistributing the gains from international capital mobility. But a high level of international capital mobility poses a problem for such a policy insofar as it enables domestic capitalists to evade the tax imposed on them. Domestic fiscal policy will be generally inadequate to undo the costs imposed on workers by capital mobility. Therefore, to the extent that workers' support is needed for major policy changes, capital mobility may not be politically sustainable when tax policy is determined at the national level and unilaterally. The solution is tax coordination at the international level. We show that, in the symmetric cases we focus on, there always exists a coordinated tax regime which is Pareto-superior, and hence politically sustainable.

The idea that a decentralized (Nash) equilibrium in taxes is suboptimal in a world of capital mobility is well recognized. In particular, tax competition is generally expected to drive tax rates down to inefficiently low levels. Our contribution to this literature is twofold. First, as a normative matter, we make the point that tax competition becomes a more serious problem than is usually recognized when one takes into account some of the redistributive effects of capital mobility. As we show in our model, Paretooptimality requires that capital mobility be matched with an increase in the tax on capital (and not simply with the maintenance of the tax at a pre-existing level). Capital mobility requires compensatory transfers that, thanks to mobility, are now harder to finance. Second, as a positive matter, we argue that capital mobility may not be a political equilibrium when workers are sufficiently influential in the political sphere and taxes are not coordinated internationally.

Our argument for international tax coordination as a mechanism for getting out of a political impasse - reaping the benefits of capital mobility while compensating the losers- has, to our knowledge, not been developed in the academic literature. The discussion on tax coordination typically focuses on the question of the extent to which capital mobility drives national tax 
rates down, and on issues of institutional design regarding the selection of a cooperative tax rate at the international level (see for example Gordon 1992 and Razin and Sadka 1991; Persson and Tabellini 1995 provide a nice survey).

A paper by Persson and Tabellini (1992) is noteworthy in that it does make the connection with domestic politics. This paper analyzes how national tax rates are determined in a model of a representative democracy where voters take into account the constraint imposed by capital mobility. They show that the downward pressure on tax rates can be ameliorated by voters electing governments with a stronger preference for taxes. Hence domestic politics partially offsets the inefficiency of Nash-Cournot behavior at the international level. Our logic differs from Persson and Tabellini (1992) in one key respect: we require that no significant group (i.e., labor) be a net loser. This constraint raises the possibility that the compensatory adjustments in national tax rates may not be feasible in the absence of explicit coordination.

\section{The model}

We will use a very simple model to capture the intuition described in the introduction. We assume a world with two symmetric countries, home and foreign. Both countries produce and trade an identical consumption good. This good is produced under constant returns to scale and through a combination of capital and labor. Each country is affected by a particular productivity shock, $\varepsilon$ and $\varepsilon^{*}$ whose joint distribution has a mean $(\bar{\varepsilon}, \bar{\varepsilon})$ and a variance-covariance matrix ${ }^{1}$

$$
\left(\begin{array}{cc}
\sigma^{2} & \mu \\
\mu & \sigma^{2}
\end{array}\right)
$$

\footnotetext{
${ }^{1}$ We denote with a star $(*)$ all the foreign variables. Unless required otherwise, we describe functions and variables only for the home country.
} 
Let the production function be described by

$$
F(K, L)=L(f(k)+\varepsilon k)
$$

with the usual regularity conditions: $F_{K}>0, F_{L}>0, F_{K K}<0, F_{L L}<0$ and $F_{K L}>0$. If we normalize the consumption price to one, factor remunerations are defined by:

$$
r=f^{\prime}+\varepsilon \text { and } w=f-k f^{\prime} .
$$

The demand for capital is given by

$$
k=f^{\prime-1}(r-\varepsilon)
$$

with $k^{\prime}=\frac{1}{f^{\prime \prime}}$.

The population of each country is assumed to be divided into two groups: workers and capital owners. Both types are risk averse and share the same indirect utility function; $V(I)$ where $I$ is the disposable income and $V^{\prime}>0$ and $V^{\prime \prime}<0$. The groups only differ in their factor endowment. Workers own one unit of labor and capital owners one unit of capital. Factors of production are inelastically supplied. Each country is endowed with $\bar{L}$ units of labor and $\bar{K}$ units of capital. Therefore, the net income of a capital owner and a worker are respectively given by

$$
I^{k}=r-T \text { and } I^{l}=w+T \bar{k}
$$

where $T$ is the source based per unit capital income tax at home, $\bar{k}=\frac{\bar{K}}{\bar{L}}$ and the $l(k)$ superscript denotes a worker (capital owner) variable.

Consider the following problem. Both countries have to decide whether to liberalize their capital market or not. By capital market liberalization, we mean full mobility of capital among countries.

The sequence of events is the following:

(1) Capital owners propose a tax scheme to the workers in exchange for capital market liberalization, in both countries simultaneously. 
(2) Productivity shocks unfold.

(3) Equilibrium investment and remuneration are determined.

To asses the level of transfers needed to compensate workers for the increased risk they face, we first compute the welfare of each type of agent with and without capital mobility. We then check if this transfer level is sustainable, i.e. whether the pair of capital taxes is a Nash equilibrium of the game played between the capitalists of both countries.

\subsection{Welfare effect of shocks when capital is immobile}

Because the decision on the liberalization of the capital market is taken before the productivity shock unfolds, we consider the expected welfare of each type of agent. When the capital market is not liberalized, equilibrium values depend, in each country, only on the local productivity shock. Taking the Taylor expansion of the utility function $V(I)$ around $\bar{\varepsilon}$, expected utility can be approximated in the following way: ${ }^{2}$

$$
\begin{aligned}
\widehat{E V} & =E\left[V+\frac{d V}{d \varepsilon}(\varepsilon-\bar{\varepsilon})+\frac{1}{2} \frac{d^{2} V}{d \varepsilon^{2}}(\varepsilon-\bar{\varepsilon})^{2}\right] \\
& =V+\frac{1}{2} \frac{d^{2} V}{d \varepsilon^{2}} \sigma^{2} \\
& =V+\frac{1}{2} \sigma^{2}\left(I_{\varepsilon}^{2} V^{\prime \prime}+I_{\varepsilon} I_{\varepsilon \varepsilon} V^{\prime}\right)
\end{aligned}
$$

where $V$ stands for $V(I(\bar{\varepsilon}, T)), I_{\varepsilon}$ for $\frac{\partial I}{\partial \varepsilon}$ and $I_{\varepsilon \varepsilon}$ for $\frac{\partial^{2} I}{\partial \varepsilon^{2}}$. The remuneration of production factors depends only on the national productivity shocks. Differentiating the agents' income described in (1) with respect to the shock;

$$
I_{\varepsilon}^{k}=1 \text { and } I_{\varepsilon \varepsilon}^{k}=0
$$

and

$$
I_{\varepsilon}^{l}=0 \text { and } I_{\varepsilon \varepsilon}^{l}=0
$$

\footnotetext{
${ }^{2}$ In this section, all functions, except when mentioned, are evaluated at $\bar{\varepsilon}$.
} 
Thus

$$
\widehat{E V}^{k}=V^{k}+\frac{1}{2} \sigma^{2} V^{k \prime \prime} \text { and } \widehat{E V}^{l}=V^{l}
$$

Because of the production function we use, capital owners are the only ones affected by the productivity shock. The larger the variance of the shock, the lower the welfare of the capital owners. The invariance of workers' welfare to the production shock is a useful simplification; we shall briefly consider the implications of relaxing this result later on.

\subsection{Welfare effect of shocks when capital is perfectly mobile}

In our model, the liberalization of the capital market reallocates the distribution of risk among the two classes of agents. When national productivity shocks are idiosyncratic, capital mobility enables capital owners to diversify their risks, and it is therefore welfare-improving for them. For workers, on the other hand, capital mobility results in exposure to income risk. A negative (positive) productivity shock at home induces a capital outflow (inflow) and a reduction (increase) in wages. Moreover, workers are now also affected by shocks in the foreign country, as domestic and foreign capital respond to changes in productivity abroad.

Let us see formally how this takes place in our model. The expected welfare of each class of agent now depends on the shocks in both countries. We approximate expected welfare as before via a Taylor expansion around $\left(\bar{\varepsilon}, \bar{\varepsilon}^{*}\right)$ :

$$
\begin{aligned}
E V(I)= & V+\frac{1}{2}\left(I_{\varepsilon \varepsilon} \sigma^{2}+I_{\varepsilon^{*} \varepsilon^{*}} \sigma^{2}+2 I_{\varepsilon^{*} \varepsilon} \mu\right) V^{\prime}+ \\
& \frac{1}{2}\left(I_{\varepsilon}^{2} \sigma^{2}+I_{\varepsilon^{*}}^{2} \sigma^{2}+2 I_{\varepsilon^{*}} I_{\varepsilon} \mu\right) V^{\prime \prime}
\end{aligned}
$$

where $V$ stands for $V\left(I\left(\bar{\varepsilon}, \bar{\varepsilon}^{*}, T, T^{*}\right)\right)$.

Perfect capital mobility and the source based nature of the capital tax induce the following arbitrage conditions:

$$
f^{\prime}+\varepsilon-T=f^{\prime *}+\varepsilon^{*}-T^{*}=\rho
$$


where $\rho$ is the international remuneration of capital. Moreover the capital market clearing condition implicitly defines $\rho\left(T, T^{*}, \varepsilon, \varepsilon^{*}\right)$

$$
k(\rho, T, \varepsilon)+k^{*}\left(\rho, T^{*}, \varepsilon^{*}\right)=2 \bar{K}
$$

A positive productivity shock increases the demand for capital and therefore $\rho$ has to adjust upward. Formally, $\rho_{\varepsilon}=\frac{k^{\prime}}{k^{\prime}+k^{*^{\prime}}}>0$ and if, for the ease of computation, we assume that $f^{\prime \prime \prime}=0^{3}$, then

$$
\rho_{\varepsilon \varepsilon}=0 \text { and } \rho_{\varepsilon \varepsilon^{*}}=0
$$

For use below, let us compute the following derivatives:

$$
\frac{d k}{d \varepsilon}=\left(\rho_{\varepsilon}-1\right) k^{\prime}=-\frac{k^{*^{\prime}} k^{\prime}}{k^{\prime}+k^{* \prime}}=-\frac{d k^{*}}{d \varepsilon}>0 \text { and } \frac{d^{2} k}{d \varepsilon^{2}}=0 .
$$

Moreover, fiscal policies influence the international remuneration of capital in the following way: $\rho_{T}=-\frac{k^{\prime}}{k^{\prime}+k^{*}}<0$.

\subsubsection{The expected welfare of capital owners}

Taking the Taylor expansion of the utility function developed in (4), expected welfare is given by

$$
E V^{k}=V^{k}+\frac{1}{2\left(k^{\prime}+k^{* \prime}\right)^{2}}\left(k^{\prime 2} \sigma^{2}+k^{*^{\prime} 2} \sigma^{2}+2 k^{\prime} k^{*^{\prime}} \mu\right) V^{k \prime \prime}
$$

Since we assume that the countries are symmetric, the tax levels in the absence of capital mobility are equal. Therefore, for these particular tax levels, $k^{\prime}=k^{*^{\prime}}{ }^{4}$ This allows us to rewrite expected welfare as follows:

$$
E V^{k}=V^{k}+\frac{\left(\sigma^{2}+\mu\right)}{4} V^{k \prime \prime}
$$

\footnotetext{
${ }^{3}$ This symplifying assumption helps us to asses neatly the effect of the capital mobility on the welfare of each type of agent. Indeed, the sign of $f^{\prime \prime \prime}$ would influence the sign of the $V^{\prime}$ coefficient in (4). For instance, this coefficient is positive for the capital owners when $f^{\prime \prime \prime}$ is positive. This means that when $f^{\prime \prime \prime}$ is too negative, capital mobility could become detrimental to the capital owners.

${ }^{4}$ Remember that the functions are evaluated at $\left(\bar{\varepsilon}, \bar{\varepsilon}^{*}\right)$.
} 
Comparing this value to the expected welfare of capital owners when capital is immobile, we get

$$
E V^{k}-\widehat{E V^{k}}=\frac{1}{4}\left(\mu-\sigma^{2}\right) V^{k \prime \prime}
$$

for $T=T^{*}$. This means that as long as shocks are not perfectly positively correlated (i.e. $\mu<\sigma^{2}$ ), the liberalization of the capital market enables the capitalists to diversify their risk and is therefore welfare improving.

\subsubsection{The expected welfare of workers}

Let us now turn to the effect on workers' expected welfare. The net income of a worker is his gross wage plus direct subsidy.

$$
I^{l}=w+T k
$$

where $k$ depends on the amount of capital invested at home. As we saw in the case of no capital mobility, the productivity shock does not directly affect the wage. Indeed it is through capital movements that workers are affected. Moreover, workers are affected by the productivity shock of both countries. A positive shock at home (abroad) induces, for home, a capital inflow (outflow) and therefore an increase (decrease) of the gross wage and, given the capital tax level, an increase (decrease) in the transfer. It is important to note that transfers are decided ex-ante. Formally,

$$
I_{\varepsilon}^{l}=\frac{d w}{d \varepsilon}+T \frac{d k}{d \varepsilon}=-\frac{k^{*^{\prime}}}{k^{\prime}+k^{*^{\prime}}}\left(T k^{\prime}-k\right)=-I_{\varepsilon^{*}}^{l}>0
$$

Taking the second derivatives we get

$$
I_{\varepsilon \varepsilon}^{l}=\frac{k^{\prime} k^{* \prime 2}}{\left(k^{*^{\prime}}+k^{\prime}\right)^{2}}=I_{\varepsilon^{*} \varepsilon^{*}}^{l}=-I_{\varepsilon \varepsilon^{*}}^{l}
$$

This give us an expected welfare

$$
E V^{l}=V^{l}+\frac{1}{2}\left(\sigma^{2}-\mu\right) \frac{k^{*^{\prime} 2}}{\left(k^{*^{\prime}}+k^{\prime}\right)^{2}}\left(V^{l \prime} k^{\prime}+V^{l \prime \prime}\left(k^{\prime} T-k\right)^{2}\right)
$$


Taking values at the symmetric equilibrium,

$$
E V^{l}=V^{l}+\frac{1}{2}\left(\sigma^{2}-\mu\right)\left(V^{l \prime} k^{\prime}+V^{l \prime \prime}\left(k^{\prime} T-k\right)^{2}\right)
$$

Comparing this value to the expected welfare of the workers when capital is immobile, we get

$$
E V^{l}-\widehat{E V^{l}}=\frac{1}{2}\left(\sigma^{2}-\mu\right)\left(V^{l \prime} k^{\prime}+V^{l \prime \prime}\left(k^{\prime} T-k\right)^{2}\right)<0
$$

when $T=T^{*}$.

Workers are therefore hurt by capital mobility and need compensation to accept capital market liberalization. Let $\bar{T}\left(T^{*}\right)$ and $\bar{T}^{*}(T)$ be the set of taxes that exactly compensates the home and foreign workers respectively, given the tax decided in the other country. These are implicitly defined by

$$
E V^{l}=\widehat{E V}^{l} \text { and } E V^{l *}={\widehat{E V^{l}}}^{*} \text {. }
$$

From (6) and (3), we see that the more negative the correlation between the shocks, the larger the required transfer.

\subsection{Fiscal policy}

Up to now we have considered the level of the transfer needed to compensate workers, but we have not yet described how fiscal decisions are made. We assume in this paper that a liberalization decision is politically feasible if no group loses from it. Formally, the decision takes the following form: Capital owners make a "take it or leave it" offer to the workers consisting of a level of transfer (more precisely a source based capital income tax) and a liberalization proposition. Workers accept it if the transfer compensates the welfare loss they incur because of additional exposure to risk. We know that when shocks are not perfectly correlated, there is an aggregate gain from liberalization. Capital owners are therefore willing to compensate the workers.

But if countries decide not to coordinate, capital owners have to take into account the fiscal decision of the other country. As was shown in the previous 
section, the level of capital tax needed to compensate workers depends on the tax imposed in the other country. In the following sections, we show that when taxes are decided non-cooperatively, there are cases where none of the capital tax rates that would induce the workers to accept the capital market liberalization is sustainable in equilibrium. The difficulty is that even if capitalists are willing to pay the transfers needed to liberalize the capital market, they are not able to commit themselves to do it. Moreover, there is competition between the two countries to attract capital. Given the tax rate of the other country, it could be profitable for both capital owners and workers to decrease their tax level. Capital owners get a higher net remuneration. For workers, the loss of revenue from the tax on the already invested capital can be more than compensated by the increase of the tax base.

We later show that if there is fiscal coordination, capital market liberalization will always be approved.

\subsubsection{Fiscal competition}

In the first stage, we shall assume that countries decide their fiscal policy non-cooperatively. We therefore solve a non-cooperative game between the two countries whose players are the capital owners of each country, where strategies are the capital taxes, and where payoffs are defined as follows:

$$
\Pi\left(T, T^{*}\right)= \begin{cases}E V^{k}\left(T, T^{*}\right) & \text { when } E V^{l}\left(T, T^{*}\right) \geq \widehat{E V^{l}} \\ \qquad V^{k} & \text { when } E V^{l}\left(T, T^{*}\right)<\widehat{E V^{l}}\end{cases}
$$

at home and,

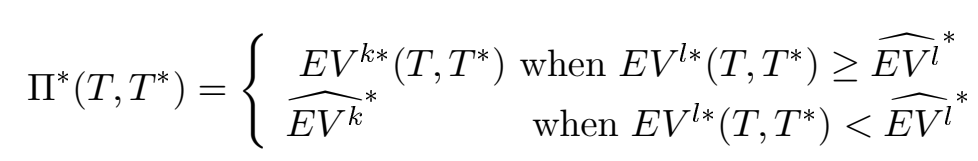

abroad.

As $E V^{k}\left(T, T^{*}\right)$ is a decreasing function of $T$ and as there are gains from capital market liberalization, the best reply functions are going to be the smallest capital tax that satisfies the workers' welfare constraint. 


$$
\begin{aligned}
& T^{b r}\left(T^{*}\right)=\left\{\begin{array}{cc}
\min \left\{\bar{T}\left(T^{*}\right)\right\} & \text { when } \bar{T}\left(T^{*}\right) \text { is defined } \\
0 & \text { otherwise }
\end{array}\right. \\
& \text { and } T^{b r^{*}}(T)=\left\{\begin{array}{cc}
\min \left\{\bar{T}^{*}(T)\right\} \text { when } \bar{T}\left(T^{*}\right) \text { is defined } \\
0 \quad \text { otherwise }
\end{array}\right.
\end{aligned}
$$

at home and abroad, respectively. ${ }^{5}$

There always exists at least one equilibrium to this game; that is, both countries announce a zero tax and no capital mobility is allowed. The question is whether there exist other symmetric equilibria under which capital mobility is allowed.

As free trade in capital is potentially Pareto improving in each country, there exist symmetric pairs of taxes that fulfill workers' welfare constraint and that capital owners prefer to the case of no capital mobility. Let us focus on the smallest of these symmetric pair of taxes $(\widetilde{T}, \widetilde{T})$. For this to be a non-cooperative equilibrium, it should be the case that there are no profitable deviations. An increase of the capital tax is never going to benefit the capital owner. Let us then consider a tax reduction by the home country. This deviation benefits the capitalists as it increases $\rho$. This will not be profitable if it violates the workers' welfare constraint, i.e. if

$$
\left.\frac{d E V^{l}}{d T}\right|_{(\widetilde{T}, \widetilde{T})}>0
$$

Differentiating (5), we have that

$$
\frac{d E V^{l}}{d T}=\left(V^{\prime}+\frac{\sigma^{2}-\mu}{2} k^{\prime} V^{\prime \prime}\right) \frac{d I^{l}}{d T}
$$

Because the first part of the left hand side is always positive, $\frac{d E V^{l}}{d T}$ has the same sign as $\frac{d I^{l}}{d T}$.

$$
\frac{d I^{l}}{d T}=k^{\prime}\left(\rho_{T}+1\right) T-k \rho_{T} \lessgtr 0 \Longleftrightarrow T \gtrless T^{\lim }\left(T, T^{*}\right)=\frac{k \rho_{T}}{k^{\prime}\left(\rho_{T}+1\right)}=-\frac{k}{k^{*^{\prime}}}
$$

${ }^{5} \bar{T}^{*}(T)$ or $\bar{T}\left(T^{*}\right)$ are not defined when given the tax announced by the other country, there doesn't exist a tax level that would compensate the workers. 
This means that when $\widetilde{T}$ is not larger than $T^{\lim }(\widetilde{T}, \widetilde{T})$ there exists a second equilibrium under which free trade in capital occurs and workers are not worse off than under autarchy. But when $\widetilde{T}$ is larger than this value, no capital market liberalization would be politically feasible without fiscal coordination.

The intuition is the following: a decrease in $T$ increases the expected capital investment at home, which implies an increase in the workers' expected remuneration and of the tax base. When $\widetilde{T}$ is large, these two effects more than compensate the loss of revenue due to the decrease in the tax level. Therefore, a unilateral decrease of the capital tax rate increases the expected income for the workers. We show in the appendix that when $\widetilde{T}>T^{\lim }(\widetilde{T}, \widetilde{T})$, no asymmetric equilibrium exists either.

We therefore conclude the following. In the absence of fiscal coordination, capital market liberalization will not be politically feasible when the transfer required to compensate workers is large (i.e., when agents are very risk averse or when shocks are highly negatively correlated).

\subsubsection{Fiscal coordination}

We showed above that there does not always exist an equilibrium to the noncooperative fiscal game between the two countries, and therefore, without coordination, profitable capital market liberalization could be rejected.

Would tax coordination improve the situation?

In the case of coordination, we assume that there is bargaining between the two countries' capital owners in order to decide the level at which capital taxes are set. Because bargaining solutions have to be efficient ex-ante we restrict ourself to symmetric taxation. The bargaining outcome is then the $(\widetilde{T}, \widetilde{T})$ tax levels that we described above. This solution maximizes the joint welfare of the capital owners given the workers' welfare constraint.

Proposition 1 When agents are very risk averse and when productivity shocks are highly negatively correlated, fiscal coordination is a necessary con- 
dition for capital market liberalization to be politically sustainable. Moreover, there always exists a coordinated tax regime which is Pareto-superior, and hence politically sustainable.

This proposition emphasizes the need for fiscal coordination to enable capital market liberalization. In this model, fiscal coordination enables capitalists to commit to redistribution and therefore allows the workers to accept the liberalization of capital markets.

\section{Generalization}

The model we have considered so far is highly stylized. We have chosen assumptions that enable us to make our point as cleanly as possible. In this section we discuss a number of generalizations, and suggest that relaxing our particular assumptions would not alter the substance of our conclusions (while they would greatly complicate the algebra).

The type of shocks. Our productivity shocks take the linear-additive form and their direct effect is limited to the returns on capital. This specification has the advantage that it allows us to isolate the effect of capital market integration on the risk exposure of workers. It renders transparent the transfer of risk from capital owners to workers as capital mobility increases. However, the point that risk-averse workers may lose from capital-market liberalization is more general. Assuming that labor is inelastically supplied, workers end up facing additional income risk whenever the movement of capital in response to idiosyncratic country shocks induces additional fluctuations in real wages. Standard production theory suggests that the demand for any factor (labor) becomes more variable when the supply of other factors (capital) is more responsive to changes in the economic environment.

To see this, express the marginal revenue product of labor as $R(K, L, \theta)$, with $K$ and $L$ standing for the capital and labor endowments and $\theta$ for an exogenous productivity shock. Let $\theta$ be a positive shock, such that 
$R_{\theta}()>$.0 . Further, $R_{K}()>$.0 . Equilibrium in the labor market requires $w=R(K, L, \theta)$. With labor inelastically supplied $(d L=0)$, we get

$$
\frac{d w}{d \theta}=R_{\theta}+R_{k} \frac{d K}{d \theta}
$$

It is natural to assume that positive (negative) shocks result in a capital inflow (outflow) in a world with capital mobility: $\frac{d K}{d \theta}>0$. It is evident from this expression that capital mobility increases the amplitude of fluctuations in wages for a broad range of shocks, including changes in economy-wide productivity or the terms of trade. The more general case is developed in Rodrik (1997, Appendix A). Hence, the idea that capital mobility imposes a negative risk-exposure externality on workers will survive many plausible extensions of the model outlined above.

The tax instrument. The model could be extended to more sophisticated tax instruments. In this paper, we consider unconditional source based capital taxation. Allowing for an efficient residency based capital tax would, as in most of the literature on fiscal competition, suppress the need for coordination. Unfortunately, this type of tax system is difficult to monitor and therefore leads to tax evasion. Hence, the use of source based taxation can be justified by practical considerations.

Still, a more sophisticated source-based capital tax conditional on the realization of the shock could be more efficient. This type of fiscal instrument would entail a negative capital tax when a positive shock occurs and a positive one in the case of a negative shock. However, the logic of our argument would not change. What is important is that with free trade in capital, the need for redistribution increases in tandem with the cost of levying taxes (absent tax coordination). The possibility that compensatory adjustments in national tax rates may not be feasible in the absence of explicit coordination would continue to exist.

The political mechanism. The social choice mechanism we use serves to highlight the potential conflict of interest between workers and capitalists 
on account of risk exposure where capital mobility is concerned. It has the peculiarity that each type of agent has a veto power and that it is the capital owners who are the proposers of policy. Our results will go through in some other schemes as well. For example, we could allow the workers instead to make a take it or leave it offer to the capital owners. This would obviously change the equilibrium level of capital taxation in the case of liberalization. But it would not alter the fact that workers may prefer to avoid capitalmarket liberalization in anticipation of becoming worse off, as indeed they would be in a non-cooperative equilibrium where the level of transfers needed to compensate them is sufficiently high. The same logic would also apply in a median-voter model where the median voter is a "worker" or an individual with a capital-labor endowment lower than the economy-wide average.

Other social choice mechanisms can yield different outcomes. If decisions are made by a utilitarian social planner, capital market liberalization will always be a winner in a symmetric set up. More generally, when the political system behaves as if it maximizes a weighted average of the expected utilities of the two groups, liberalization will emerge as the equilibrium outcome (even absent tax coordination) as long as the implicit weight on labor is not too large.

The all-or-nothing regime with regard to capital mobility. In this paper, we either have full liberalization with no cost of mobility for capital or no mobility at all. Obviously, capital market liberalization could be a slow process where the costs of capital mobility go down over time. Introducing a mobility cost would alleviate the fiscal competition, and reduce the gains from capital mobility. It is easy to see that the lower the cost of capital mobility, the larger the need for redistribution and the greater the difficulty in levying taxes. Our result would therefore be that when the cost of capital mobility goes below a certain threshold, the process of capital market liberalization would need fiscal coordination in order to continue.

Capital accumulation. Our model is static, with a fixed endowment of 
capital in the world economy as a whole. In a dynamic model, the possibility of capital accumulation as well as of a richer set of strategic interactions between national fiscal authorities can complicate the picture significantly. While we expect the conflict of interest we have identified here to survive in a dynamic setting, there is one ameliorating factor that is worth pointing out. Since capital mobility allows capitalists to reduce their exposure to risk (partly by shifting it on to workers), it may also enhance the rate of capital accumulation. This would have a beneficial effect on workers in all countries, as it would increase the rate of growth of real wages. Consequently, it is possible that a higher growth trend in real wages would more than make up for the increased risk that workers bear.

Structure of the economy. In our economy there is a single good produced in both countries. This allows us to establish, in the simplest possible framework, a positive relationship between the capital stock employed in the economy and the level of real wages. One can imagine alternative settings where the real wage is independent of the capital stock. For example, in a model with two traded goods and assuming incomplete specialization, the real wage would be pinned down by relative goods prices, and the domestic capital stock would influence real wages only to the extent that product prices are affected. To the extent that a capital outflow does not affect domestic labor adversely, our results would not go through. This is a matter that can only be settled empirically. But a model in which real wages are positively related to the capital stock does not strike us as being unreasonable (or too restrictive) for purposes of policy analysis.

\section{Conclusion}

We have identified in this paper a source of political tension in capital market liberalization. Capital market liberalization calls for more redistribution while making this redistribution difficult. We showed that when the transfer required to compensate workers is large enough, capital market liberaliza- 
tion, while efficient, is not politically sustainable without fiscal coordination. Fiscal coordination acts as a commitment device for the capitalists to pay their tax following capital market liberalization.

In reality, liberalization decisions are not so abrupt. Capital movements are impeded not only by legal barriers, but also by other limitations, like differences in legal systems, language or cultural habits, or even by technological problems. What our paper argues is that the long process necessary for perfect capital mobility could be interrupted if international fiscal coordination does not take place.

The form that the coordination should take is another question. In this paper, coordination is done through full harmonization. The feasibility of such harmonization drastically depends on the assumption we made about the symmetry between the two countries. With a larger number of countries or in the presence of asymmetries, it is likely that the desirable coordination mechanism would look quite different. ${ }^{6}$

\footnotetext{
${ }^{6}$ See van Ypersele (1998) for a related discussion.
} 


\section{Appendix}

When $\widetilde{T}>T^{\lim }(\widetilde{T}, \widetilde{T})$, no asymmetric equilibria exist in the game defined by (8) and (9).

Proof. We limit our proof to cases where the foreign country announces higher capital tax than the home country.

We first show that $\left(\widehat{T}, \widehat{T}^{*}\right)$ with $\widehat{T}^{*}>T^{\lim }(\widetilde{T}, \widetilde{T})$ and $\widehat{T}<\widehat{T}^{*}$ never are equilibria.

To see this note that $T^{\lim }(T, T)=T^{* \lim }(T, T)=\frac{-\bar{k}}{k^{\prime}}$ for all $T$ and $\frac{d T^{*} \lim \left(T, T^{*}\right)}{d T}>0$. Therefore $\widehat{T}^{*}>T^{\lim }(\widetilde{T}, \widetilde{T})=T^{* \lim }\left(\widehat{T}^{*}, \widehat{T}^{*}\right)>T^{*} \lim \left(\widehat{T}, \widehat{T}^{*}\right)$ when $\widehat{T}<\widehat{T}^{*}$.

This means that $\left(\widehat{T}, \widehat{T}^{*}\right)$ is an equilibrium, since as long as $\widehat{T}^{*}>T^{*} \lim \left(\widehat{T}, \widehat{T}^{*}\right)$ both foreign workers and foreign capitalists prefer to decrease the capital tax.

Second we show that $\left(\widehat{T}, \widehat{T}^{*}\right)$ with $\widehat{T}^{*} \leq T^{\lim }(\widetilde{T}, \widetilde{T})<\widetilde{T}$ and $\widehat{T}<\widehat{T}^{*}$ never are equilibria.

By definition of $\widetilde{T}$, we know that for pairs of taxes that are symmetric and lower than $\widetilde{T}$, the workers' welfare constraint are violated. Therefore as $\widehat{T}^{*} \leq T^{\lim }\left(\widehat{T}^{*}, \widehat{T}^{*}\right)$ and as $\frac{d T^{\lim }\left(T, T^{*}\right)}{d T}<0$, given $\widehat{T}^{*}$, none of the $\widehat{T}<$ $\widehat{T}^{*}$ could rebalance the home workers' welfare constraint. When the home workers' welfare constraint is not satisfied, the liberalization is blocked and it is optimal for the home capital owners to announce the smallest capital $\operatorname{tax}$. 


\section{References}

[1] Garrett, Geoffrey, "Capital Mobility, Trade, and the Domestic Politics of Economic Policy," International Organization, 49(4), Autumn 1995, 657-687.

[2] Gordon, R.H., "Can Capital Income Taxes Survive in Open Economies?" The Journal of Finance, 47, 1992, 1159-1180.

[3] Obstfeld, Maurice, "Risk-Taking, Global Diversification, and Growth," American Economic Review, 84(5), December 1994, 1310-1329.

[4] Persson, Torsten, and Guido Tabellini, "The Politics of 1992: Fiscal Policy and European Integration," Review of Economic Studies, 59, 1992, 689-702.

[5] Persson, Torsten, and Guido Tabellini," Double-Edged Incentives: Institutions and Policy Coordination," in G.M. Grossman and K. Rogoff, eds., Handbook of International Economics, vol. III, Amsterdam, NorthHolland, 1995.

[6] Razin, Assaf, and Efraim Sadka, "International Fiscal Policy Coordination and Competition: An Exposition," NBER Working Paper No. 3779, 1991.

[7] Rodrik, Dani, Has Globalization Gone Too Far?, Institute for International Economics, Washington, DC, 1997.

[8] Rodrik, Dani, "Why Do More Open Economies Have Bigger Governments?" Journal of Political Economy, October 1998.

[9] van Ypersele T. Coordination of Capital Taxation Among a Large Number of Asymmetric Countries, CenTER discussion paper no98137, 1998 